\title{
Biometric Private Iris Recognition from an Image at Long Distance
}

\author{
Swati D. Shirke, C. Rajabhushnam
}

\begin{abstract}
The specially finished annular element of the person eye which is remotely visible is - iris. This iris recognition is useful to identify the individual. In number of applications the iris recognition system is used. Most of the countries uses biometric system for security purpose such that in airfield boarding, custom clearance, congregation entrance and so on. The Indian government also uses biometric system for identification of citizen in different applications like as in rashan shop, Aadhar project, in different government exam forms and registration dept. etc. The customary iris recognition systems develop near infrared (NIR) sensors to obtain pictures of the iris. But in this method the iris can acquire distance less than 1 meter. In the course of the last several years, there have been different designs to plan and complete iris acknowledgment frameworks which operates at longer distance ranging from 1 meter to 60 meter. Therefore, due to such long range of iris recognition systems and iris acquisition system gives to the best applications to the client. In this paper, an effective technique for iris recognition is present to identify the individual. It uses iris-recognition-at-a-distance (IAAD) system and state-of-the-art design methods to audits the iris recognition system. The primary point of this article is analyzing the criticalness and employments of IAAD systems with respect to human recognition, the review of existing IAAD structures, comparison of different method which are already implemented in literature and improvement of IAAD accuracy along with iris.
\end{abstract}

Keywords : Iris Recognition, Image Segmentation, Biometric Identification.

\section{INTRODUCTION}

In the course of the most recent decade, the use of biometric goes on increasing largely because most of the countries faces problem of fake identity. To improve the presentation of biometric system lots of efforts are taken by different researchers. Therefore most of the countries uses biometric system for security purpose such that in airport boarding, custom clearance, congregation entrance and so on. The Indian government also uses biometric system for identification of citizen in different applications like as in rashan shop, Aadhar project, in different government exam forms and registration dept. etc. There are different types of biometrics are presents such as voice, palm, finger, face, DNA, etc. But the iris recognition is the most precise and

Revised Manuscript Received on July 10, 2019.

Swati D. Shirke, Ph.D. Scholar, CSE Dept. Bharath Institute of High Education and research, Bharath University, Chennai, India,shirke.swati14@gmail.com

Dr. C. Rajabhushnam, Ph.D. Scholar,CSE Dept., Bharath Institute of High Education and research., Bharath University, Chennai, India.rajabhushanamc.cse@bharathuniv.ac.in stable biometric framework for individual identification Because the Iris is a unique thing of a person, it does not change with time and environment. It remains fixed and constant throughout the life of person. Also the error rate, applicability and precision of iris acknowledgment framework superior to the next biometric frameworks. Therefore for achieving and maintaining security, the iris recognition system plays an important role. But, for a long distance point of view the biometric recognition is a challenging assignment. The information obtained from the biometric may be poor, degraded. So it can affects on the performance of the system. Generally iris, face and gait are consider for the recognition purpose at a distance.

The portion lies in between the pupil and the white sclera of eye is called iris texture or iris region. Different features of an eye are presents in this iris region. These features are crypts, furrows, stripes, coronas, freckles, etc. These features are vary to person to person. The irises of indistinguishable twins are additionally altogether disparate. The Defense Advanced Research Projects Agency (DARPA) of United States took the most punctual effort for the biometric identification at a distance in 2001[1]. In paper [2] the detail survey of iris identification at a distance is present. The improved results of iris recognition are obtained by National Institute of Science and Technology (NIST). They identify the iris with great accuracy[3],[4]. The devices used for iris recognition in early days were not able to detect the iris at a long distance. They were identify only closer eye. Such a requirement was important to guarantee the acquisition of top quality pictures that encourage reliable recognition. Some best in class sensors and acquisition techniques have exhibited that for iris recognition at a distance. But most of the systems which works on the long distance are still in their early stages of development and research. Most of the distortion in the iris image is occurs due to the motion of person.

Therefore to reduce this type of errors some improvements are required. The Tan[5] suggested some improvements like as use fixed lenses instead of moving, design a device which can operate for both short as well as long distance, the system can operate for moving objects as well as study objects.

The methodical diagram of structuring an iris recognition at a distance (IAAD) system is presented by the paper[5]. Therefore the main aim of this proposed article is to discuss the criticalness and uses of IAAD frameworks,

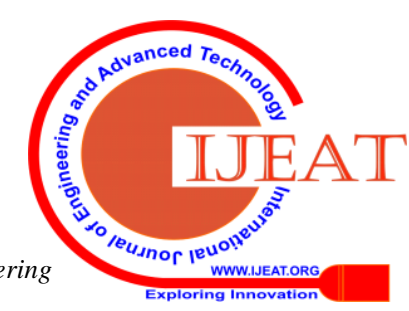


showing an all holistic perspective to the plan issue of an IAAD system, from both the hardware and programming viewpoints. International reputed journal that published research articles globally. All accepted papers should be formatted as per Journal Template. Be sure that Each author profile (min 100 word) along with photo should be included in the final paper/camera ready submission.

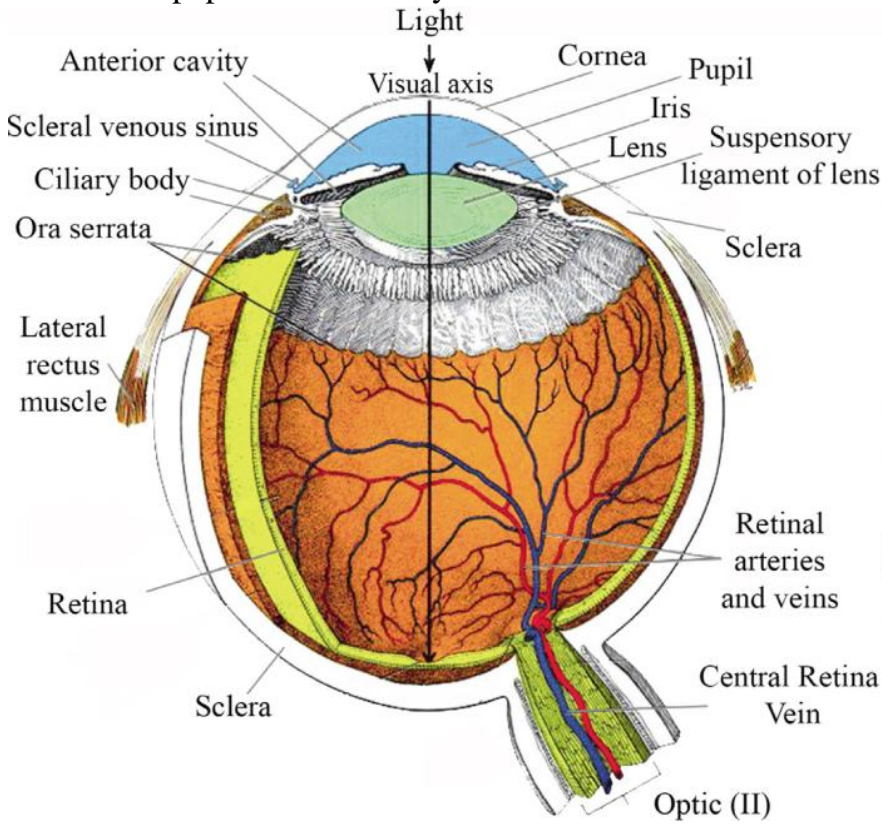

Fig. 1. Internal Structure Of Eye.

The challenges of this research work are discussed in this section and these challenges are solved in this research work.

- The major challenge associated in the iris recognition is to recover the iris features from the iris images, as the features acquired from the environments are affected by the noise sources [8].

- The local and global quality measure to estimate the iris texture distribution in the iris image for selecting the best image in the fusion or in the sequence affects the quality of the image, which is a major challenge [9].

- Sensors, which acquire the iris patterns, undergo significant transformations. This transformation poses a number of challenges in the recognition system. When it uses millions of users, then the enrollment is time-consuming and expensive in the iris recognition system. This is not feasible to re-enroll the user at every time, after a new sensor is arrived [10].

- To obtain high accuracy for the verification and identification of the iris patterns, is the major challenge, and is hard to discover the visible feature point in the iris image and tough to place their represent ability in an effective way [11].

- The iris recognition, which acquired limited controlled environments and eye images, poses a number of challenges, particularly for the images captured using visible imaging from the dynamic environments, which degrades the recognition accuracy [12].

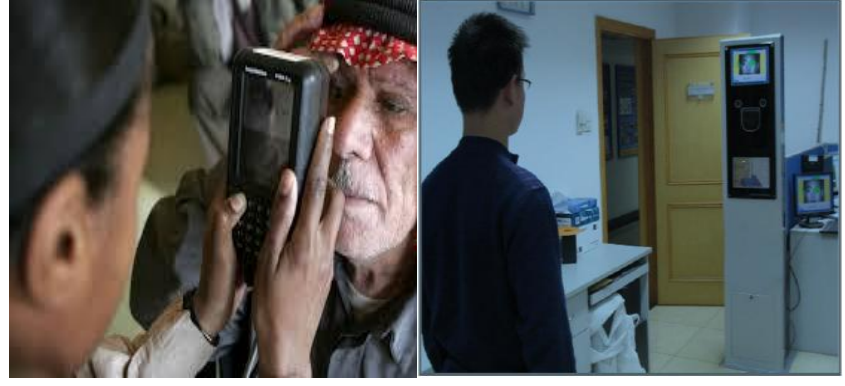

Fig. 2. Examples of Close and Long Iris Recognition.

Figure 1 shows internal structure of eye. Giving a survey of existing IAAD implementations and frameworks, featuring and talking about flow difficulties, and recommendations for future research in IAAD and examining the utilization of broadened visual data, past the iris, for improving IAAD.

It is essential to raise that there are some overview papers on the purpose of iris and visual affirmation. While the authors in [6],[7] gave an expansive and exquisitely formed analysis on general iris affirmation, they don't talk about long-go iris acknowledgment in any detail. Figure 2 shows the examples of close and long iris recognition system.

Following is the structure of the current work. The related work is presents in the section 2. The section 3 shows the various application of iris recognition system. In section 4, the flow of proposed system is present. The building blocks of proposes structure is presents in section 4 . The experimental results and the discussion are offered in Section 5. Discussion of survey is are provided in Section 6. And finally the conclusion of proposed article is presents in section 7 .

\section{RELATED WORKS}

In last decade, most of the researchers are work on the iris recognition systems for the identification of person. They use different methods for localizing the iris. An effective algorithm designed by Daugman [13] for iris recognition. The internal and external borders iris images are detected via Integro-differential operators by using this Daugman algorithm.

The 2DGabor wavelets filters are used for the feature extraction and for demodulation of iris's texture construction. It shows 1024 complex values of an iris image after applying the set of filters. Then each of these values quantized into complex plane of four quarters. And then the Hamming distance is calculated.

Then again,G. P. M. Paiva,M. V. Priya K. A. Raghavi, et al., [14] shaped a better arrangement of iris acknowledgment with the design have the option to beats the points of confinement of person's distinguishing proof approaches. They utilized a quick calculation for the reason of finding the zone of the iris. They utilized an inconclusive neural system calculation to acquire iris deterministic shapes appearing as highlight courses. These trademark highlights can be liken dependent on weighted hamming separation to demonstrate the distinction. They received a twofold coding framework to accomplish more viability. 
A course forward back spread ANN model (CFBPNN) and a FFBPNN model were used to identify patterns of the iris image in paper written by Gopikrishnan and Santhanam [15]. In light of their outcomes, they inferred that the CFBPNN model is more capable than the FFBPNN model.

An iris recognizable proof method that depends on unmistakable wavelet covariance utilizing focused ANN exhibited in Leila, et al, [16]. The build a covariance grid by methods for particular wavelet change by ANN are utilized to recognize a gathering of limits of iris profiles.

The inward and outside outskirts of the iris picture area were extracted in paper Altunkaya and Abiyev [17]. The normalization and enhancement algorithms are also presents in this paper to extract the different features of an eye image and embodied. To classify the iris patterns of iris image, an ANN classifier is designed in this paper. An adaptive learning tactic is used to train the ANN classifier. The experimental results obtained from this ANN classifier shows the proficient identification of individuals.

The globular Hough transform are presented in [18] by $O$. F. Soylemez, and B. Ergen are used for recognition purpose.

In a paper [19], A. E. Hassanien, A. Abraham, and C. Grosan identified patterns of iris via ICA coefficients, the reasonable learning device for identification of center of each class and the Euclidean distances are used to recognize the pattern of iris. Also in this paper the different noises like as noises occurs due to light are removed from eyelashes and eyelids. The blurred iris image is also accurately recognized by this method.

The different features of an iris image are extracted in the paper written by Ma, Wang, and Tan [20]. They uses 2D Haar wavelet used to perform the matching process.

The pyramid of Laplacian with four resolution levels are used to produce the code of the iris and Hough transform is used to localize the iris is employed in Wildes [21].

The iris conformity depending on two variation functions and the Hough transform to localization the iris are used by Boles [22].

The weighted gradients are used in the paper Masek and Kovesi [23] for the iris recognition. The circular Hough-transform and modified canny edge detector are also used in this paper.

Alaa S. Al Waisy et al. [24] developed a deep learning approach termed as IrisConvNet, which was the combination of the Softmax classifier and the $\mathrm{CNN}$ to retrieve the discriminative features in the iris image.

It used the training methodology to control the overfitting and to enhance the generalization capability of the neural network.

Liu $\mathrm{N}$ et al. [25] developed a code-level approach for iris recognition. It modelled the binary feature codes in the heterogeneous iris images and transformed the iris templates into homogenous iris template. However, some other biometric modalities were extended to use.

Ahmadi N. and Akbarizadeh G [26] introduced human iris recognition approach by combining the Particle Swarm Optimisation (PSO) algorithm and multi-layer perceptron Neural Network (NN) in order to enhance the generalisation performance. It used the gabor feature extraction to extract the features on the iris images. In order to increase the efficiency and achieved better success, the PSO is combined with the fuzzy system.

Nguyen K et al. [27] developed Convolutional Neural Networks (CNNs) to express the image characteristics. The textural nuances of the iris pattern were extracted and encoded effectively using the gabor wavelets and transforms the response of the phasor using the binary code. However, the capacity of the iris templates was represented by combing the CNN with other approach.

Tan C.W. and Kumar A [28] developed a Zernike moments based encoding approach to extract and combine the localized and global iris features. It simultaneously performed the local consistency in the iris bit. The phase features were obtained from the regions and accommodate the region variation with the iris images. However, the iris matching matching was not efficiently performed.

Othman N. and Dorizzi B [29] developed a quality fusion technique to compute the quality measure for the iris image. This measure depends on the gaussian model to estimate the pure iris texture distribution. It discarded the poorly segmented pixels, but some other fusion schemes were not tested in the iris codes.

Tan C.W. and Kumar A [30] developed an iris encoding method to provide the individual identification capability for the iris images. In this encoding strategy, the textural information was exploited from the global and local iris region pixels. The iris matching provided accurate matching capability, thus it was beneficial for decision making. The encoded iris feature was represented in binary form, which allowed the iris template matching using the hamming distance.

N. Pattabhi Ramaiah and Ajay Kumar [31] developed a Naive Bayes Nearest Neighbor (NBNN) classification framework to estimate the iris patterns from the iris images. It used the bi-spectral recognition system to acquire the infra-red and visible images. This framework effectively performed the iris matching from different domains. However, it was required to recover the discriminant features simultaneously.

The different amplitude modulation frequency modulation (AM-FM) techniques shown in the paper by C. Agurto, V. Murray, E. Barriga, S. Murillo, M. Pattichis, H.Davis [32] is used to define the different retinal structures of iris image by using spectral texture analysis. In this method, the new vessels are generated.

In the paper written by G. Fahmy [33] presents super resolution algorithm that improves recognition performance of low quality in iris videos fusing images. The super resolution technique presents in this paper on an auto-regressive signature model. This auto-regressive signature model converts the low resolution pixel images into the high resolution images which is capture from long distance. In this way the blur is removed from the image. 
Then again, the work by W. Bauman , S. Barriga, M.S. Pattichis, V. Murray, Y. Honggang and C. Agurto[34] presents AM-FM alongside granulometry and the vessel division to recognize the new vessels on the optic circle.

In the paper designed by P.F. Sharp, J.A.Olson, G.J. Williams, S. Philip, A.D. Fleming, K.A. Goatman, [35] uses the gradient method to detect the new vessel. The main disadvantage of the segmentation technique is this technique does not perform vessel segmentation properly because new vessels are avoided in this method.

C.N. Doukas, I. Maglogiannis, A.A. Chatziioannou [36] presents the method an automatic technique for the quantity of small-vessel mass inside an internal outside of the eggshells. It incorporated textural information, branching points, and vessel length. The key proposal of a Suggested technique is not only line operator but also straight vessel removal for deduction of false rate.

The paper written by Bernadette and Nadia Othman Dorizzi " Impact of Quality-Based Fusion Techniques for Video-Based Iris Recognition at a Distance"[37], presents video based different image acquisition context and the local quality-based fusion scheme for image acquisition. The other researcher also developed many techniques on these topics.

In the paper written by D. Zhang, Q. Li, J. You and L. Zhang, [38] presents the model modified matched filter. This filter is used for removing the false response of an image. This improved similar filter uses two surface thresholding.

\section{Applications}

The applications used in the market for iris acknowledgment at a distance plays an important role. Some of the Test applications, gathered by their spaces, are recorded below.

1) Robotics: Robotics are used to expanding the communication separation and decreasing client requirements. The capacity of robots to perceive who they are cooperating with, can help give customized administration. The future of mechanical technology is relied upon to incorporate close interaction among people and administration based robots.

2) Military: IAAD frameworks could significantly propel observing, following, and identification of people without forcing numerous limitations. Identification assignments in battlefields are frequently completed by hand-held iris acknowledgment gadgets (e.g., PIER scanners from Securi Metrics). Such gadgets require an abnormal state of participation from members.

3) Service industry: For the client comfort in the administration business (e.g., clubs, gambling, retail stores ,banks, etc.). IAAD frameworks could be utilized for improving it.

4) Law enforcement: This is used in the police depertment application purpose in which the police can recognize a person without venturing out of their vehicle. Conceivably, they could improve the security of the two customary individuals and law execution authorities. IAAD structures have applications in bad behavior expectation and security.
5) Surveillance: Surveillance is defined as the observing of behavior, activities, or other developing information, as a rule of people for the motivation behind influencing, overseeing, coordinating, or securing them. In such manner, IAAD could be used for covert discernment and identification in a given scene or gathering. There has been an extending energy for making automated perception applications, especially using biometrics.

6) Border control: IAAD frameworks, because of their expanded obtaining separation, can diminish the client imperatives and the quantity of prominent examinations. These frameworks are commonly utilized for filtering travelers (to speed up outskirt control and screen against a watch-list), and the workers (for access control to limited regions). Iris acknowledgment frameworks are as of now being used in a few air terminals over the world (e.g., United Kingdom, Canada, United Arab Emirates, Holland, Singapore, and so forth.).

\section{Flow of Proposed System}

\section{A. Image Acquisition}

Let the height of person is $\mathrm{H}$, the digital sensor's width as $\mathrm{W}$ and focus of lens are indicated by $\mathrm{F}$, the object-image ratio as $\mathrm{M}$ and sensor pixel size as S. Iris imaging at a distance for an optical system design is critical. Therefore for iris image acquisition, the lens based on the geometry optics and the required parameters of camera are calculated.

The distance D of an objected can be calculated from equation 1 .

$$
D=F \frac{M}{S}
$$

The equation 2 shows the field depth in which the capturing volume is $\mathrm{V} \times \mathrm{A}$.

$$
\begin{aligned}
& V=M W \\
& A=M H \\
& B=2 F \frac{(M-S)(M-S)}{S}
\end{aligned}
$$

By This camera can takes a picture of human face completely with high-resolution. The lenses with its aperture size F is 15 and focal length $300 \mathrm{~mm}$. So it can capture the iris image clearly up to distance $4 \mathrm{~m}$ to $6 \mathrm{~m}$. Figure 2 shows different iris recognition systems examples close-range and long-range. Considering the above geometry optics, the lens and the camera used in this article with frame rate of thirty frames per second and the pixel size is 4-mega pixels.

The process of capturing the human face image is shown in figure 3. In figure 4 the process of extracting the eye from the face is presents. UBIRIS.V1 are the iris images which are captured from a distance from three meters away by actively searching palmprint patterns, face or iris. Therefore in this article, the UBIRIS.V1 database are used for the iris recognition. 


\section{B. Processing of an Image}

It is necessary to pre-process the iris image to enhance the different parameters an iris image such as contrast, intensity, signal to noise ratio, etc. for further processing because, the quality of iris image obtained from the camera is poor. This can be happen due to the motion of person, distance, blur or occlusions. The signal to noise ratio of iris image is improved with the help of anisotropic diffusion filter. The tool which is used for this purpose is MatLab realize the many brightness transformations. To find the rank-order information and spatial information of an iris image a weighted median (WM) filter is used and this is one of the type of median filter. The noises shot and impulse noise are rejected by the median filter. The technique which is utilized to improve the iris picture parameters are contrast stretching and histogram equalization. It only enhances the quality of image, it does not increases the information content of an image. The intensity range of an iris image is normalized to [0 1].

\section{Segmentation}

It is the initial phase in the Iris recognition framework the backbone of the complete recognition system. It aims to detect layout, centers, eyelids, eyelashes and radii, of the two iris borderline. Locating the lower as well as upper eyelid also separate eyelashes. In a segmentation step the internal and external limits of the iris area are distinguished. This can achieved by Hough transform. The Hough transform finds different shapes like as circles or ellipses of an image. With the help of the Daugman's Rubber Sheet Model the image segmentation, acquisition and feature encoding of an iris image can takes place. It is also used to improve the nature of edges introduces in the picture. The most generally utilized circle identifier is integro-differential operator and it is mathematically expressed as.

$$
M A X / G(r) * \frac{d}{d r} \int \frac{I(x, y)}{2 \pi r}
$$

where I ( $\mathrm{x}, \mathrm{y}$ ) denotes the input iris image, G(r) denotes Gaussian with a standard deviation, $r$ is the radius of circular arc. It is the convolution operation which is shown in symbol *. The line an iris image can be detected by the formula

$$
r=x \cos \theta+y \sin \theta
$$

where, $\mathrm{r}$ is quantized distance and $\theta$ is quantized angle. The $r$ and $\theta$ are considering quantized values in the pair $(r, \theta)$.

The boundary of the inner pupil and outer pupil of an iris image can be detected by using the equation,

$$
(\mathrm{m}-\mathrm{m} 0) 2+(\mathrm{p}-\mathrm{p} 0) 2=\mathrm{a} 2
$$

where, $(\mathrm{m} 0, \mathrm{p} 0)$ denotes the coordinates of a circle with radius a. The results obtained from Hough transform shows the boundary of pupil, eyelid extraction of iris image and the center of pupil.

\section{Normalization}

The Daugman's rubber sheet is an linear model that is assigned to the iris of the individual pixel based on the dilation, size and the real coordinates $(x, \theta)$, where $\mathrm{x}$ is the unit interval and $\theta$ ranges from 0 and $2 \pi$. The iris image is remapped into the polar coordinate $(\mathrm{x}, \theta)$ system from cartesian coordinated $(\mathrm{r}, \mathrm{s})$ system. Therefore the normalized polar coordinates are $(x, \theta)$ and the normal coordinates are $(r$, s). In this the segmented iris image is normalized into the block with equal in size respect to the block width $\mathrm{x}$ and angular displacement $\theta$.

Let the iris coordinates and iris boundaries of the pupil are represented as (rb, sb) and (re, se) along $\theta$ direction. The coefficient of an iris ime age will not be shifted even if the signal is distorted due to the camera and persons position.

\section{E. Feature Extraction \& Feature Matching using ScatT-loop}

The Kirsch mask is designed for the future extraction. The ScatT-loop generates the texture features for accurate iris recognition to uniquely identify the individuals. In this, the picture area contains numerous vessel sections that are firmly dispersed with various directions and have a bent in nature. So for the measurement of feature characteristics, the new vessel segments are generated from a binary vessel maps. In order to find out local features, a sub window of size $4 \times 4$ is created. In feature extraction step, the iris image is classified into new vessels image. The standardized iris picture is exposed to play out the component extraction by using ScatT-loop descriptor. The iris image are examined through this sub window. And for every sub window the number of vessel pixels and pixel passion can calculated. The loop value for the corresponding pixel is represented as,

$$
\operatorname{LOOP}\left(r^{*}, s^{*}\right)=\sum_{k=0}^{7} h\left(G^{k}-G^{*}\right) \cdot 2^{v}
$$

Where,

$$
h(d)=\left\{\begin{array}{lll}
1 & ; & \text { if } d \geq 0 \\
0 & ; & \text { Otherwise }
\end{array}\right.
$$

$\left(\mathrm{r}^{*}, \mathrm{~s}^{*}\right)$ is the centre of the intensity of iris image. Gk is the neighborhood pixel intensity, $\mathrm{G}$ is the original image pixel intensity, and $\mathrm{k}$ takes the value ranges from 0 to7. The intensity values of a pixel is determined by gradient pixel values which is operated by LGP operator. The LGP generates the constant patterns of face representation of person, which is irrespective to the intensity variation with the edges. The minimum value of the gradient among the eight neighboring pixels is considered as the threshold value. When the gradient value of the neighboring pixel is higher against the threshold, then the value assigned to the pixel is ' 1 ' otherwise the value is ' 0 '. 


\section{F. Principal Component Analysis (PCA)}

The principal components of an image can be extracts by using covariance matrix or multivariate set. The compression and decompression operations of an image ca perform by using matrix multiplication. PCA is a compression technique which compress the high dimensional vectors of an image into the low dimensional vectors and compute the parameters from the data directly. Principal Component Analysis (PCA) is a method which is used to decrease the dimensionality of an image. This method is also used for multivariate analysis of an image. To reduce the dimensionality of an image, PCA extracts less number of component. The PCA model is represented as,

$$
z_{o c 1}=D_{o c w} c_{w c 1}
$$

Where, $\mathrm{z}$ is an zero dimensional vector with the projection $\mathrm{c}$, and $\mathrm{w}$ is the feature vector dimension as $(0<\mathrm{w})$. The covariance matrix $\mathrm{E}$ is denoted as,

$$
E=\frac{1}{\rho-1} \sum_{\tau=1}^{\rho}(c-\kappa)(c-\kappa)^{G}
$$

where, $\mathrm{K}$ denotes the mean vector of $\mathrm{C}$. The Eigen vectors ßT is expressed as,

(9)

$$
\left(E-\phi_{\tau} \vartheta\right) \beta_{\tau}=0 \quad ; \quad \tau=1,2, \ldots \ldots . w
$$

where, ØT denotes the Eigen vectors of E. The projection matrix is calculated as,

$$
D=J^{G}
$$

where, $\mathrm{J}$ has 0 Eigen vectors and $\mathrm{D}$ is the ocw matrix.

The dimensionally reduced feature vector is represented as,

$$
\gamma=\left\{\gamma_{1}, \gamma_{2}, \ldots ., \gamma_{\tau} \ldots . \gamma_{o}\right\} ; \text { for }(1<\tau<o)
$$

where, 0 is the dimensionally reduced features with $0<w$.

\section{G. BPNN Based Iris Recognition}

For training multi-layer artificial neural network Back Propagation Neural Network (BPNN) is commonly used. The ANN is a computational model which is based on biological neural network.

The fundamental arrangement of the BPNN presents 1 input layer and minimum 1 hidden layer persued by output layer. Figure 3 shows the model of Back Propagation Neural Network. For categorization purpose the artificial neural network (ANN) is used. It is used to extract the information from image with the help of interconnected group of artificial network..

The detailed steps by using the BPNN ANN for Iris recognition are given below.

- Fill normalized Iris images data set which contains the feature vector values of different subjects and these are ranges from 0 to 1 .

- The normalized iris images obtained in previous section are used for training set and testing set by arbitrarily depiction out the data for training and testing.

- Generate 3 layers of iris normalized image an input, an output and a hidden layer. The dimension of the feature vector that characterizes the iris image information is equal to the number of nodes in the input.

- Use Back Propagation algorithm to train the network. This algorithm is applied until the error is smallest amount for a certain number of training epochs specified by the user.

- Evaluate the performance and the test data to the trained network.

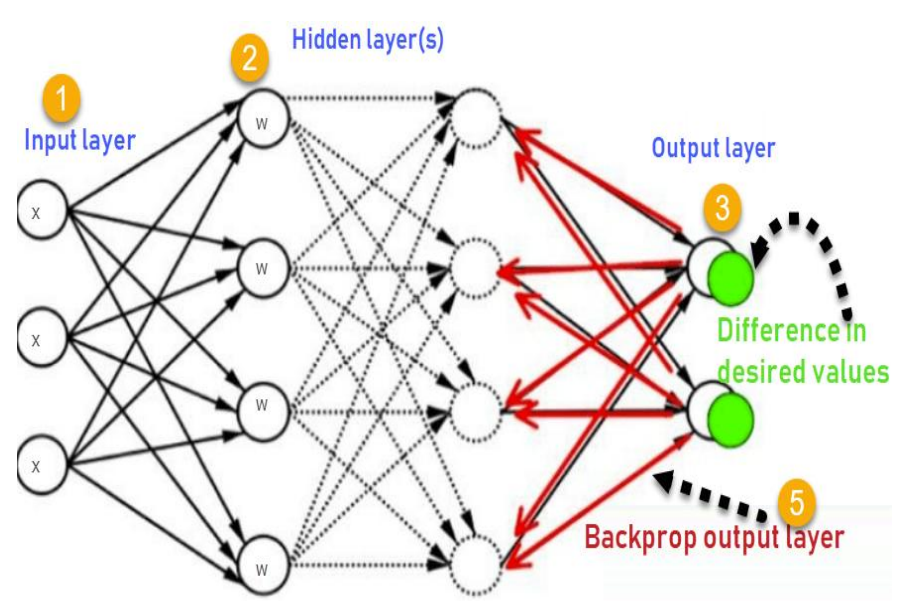

Fig. 3. Model of Back Propagation Neural Network.

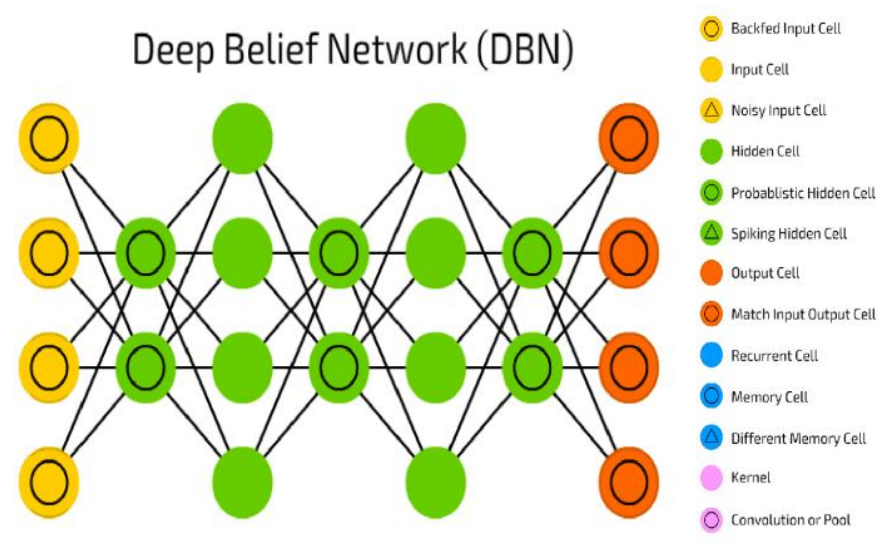

Fig. 4. Architecture of DBN classifier

\section{H. Chronological MBO-based DBN Neural Network}

The iris recognition is performed using the chronological MBO-based DBN, which is the integration of the chronological concept with the $\mathrm{MBO}$ algorithm to train $\mathrm{DBN}$ that depends on the migration features of the monarch butterfly.

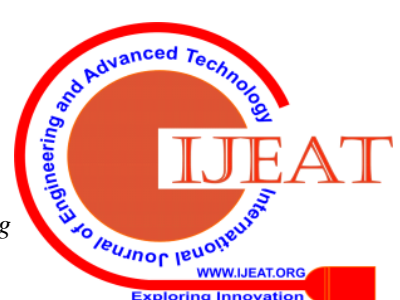


The DBN classifier using the Chronological MBO algorithm is used for the identification of a person. The non-linear complex relation presents in the real life are removed by using DBN classifier and the chronological MBO algorithm trains the DBN classifier.

Figure 4 shows the Architecture of DBN classifier. However, the searching speed and the convergence speed are enhanced by integrating the chronological concept, which defines the solutions (biases and weights) from the preceding iterations to revise the new biases and weights.

The standard $\mathrm{MBO}$ incorporates the fine tuning of parameters and the complex free computation to enhance the performance of the proposed chronological MBO-based $\mathrm{DBN}$, and the high dimensional issues are effectively dealt using MBO.

\section{Performance metrics} and accuracy are explained below.

1) Accuracy: The accuracy measures the accurateness of iris recognition based on iris modality and is represented as,

$$
\text { Accuracy }=\frac{J c+J u}{J c+R c+J u+R u}
$$

where, $\mathrm{Ju}$ denotes the true positives, and $\mathrm{Jc}$ is the true negatives. $\mathrm{Ru}$ denotes the false positives and $\mathrm{Rc}$ is the false negatives.

2) Sensitivity: Sensitivity is otherwise called True positive Rate (TPR), which is the measure of positive-ness identified correctly, and is calculated using the below equation.

$$
\text { Sensitivity }=\frac{J u}{R c+J u}
$$

3) False Rejection Ratio (FRR): FRR is the ratio of false rejection to the genuine attempts, and is expressed as,

$$
F R R=\frac{R c}{J u+R c}=1-T P R
$$

4) Specificity: Specificity or True Negative Rate (TNR) is the measure of false negatives, which are correctly located. Specificity is expressed as,

$$
\text { Specificity }=\frac{J c}{J c+R u}
$$

5) False Acceptance Rate (FAR): FAR is the ratio of false attempt to imposter attempts, and is represented as,

$$
F A R=\frac{R u}{R u+J c}=1-T N R
$$

The metrics used to evaluate the methods, are FRR, FAR,

6) Receiver Operating Characteristics (ROC): ROC refers to the relationship between TNR and TPR, which is used to compute the performance of the system.

\section{BUILDING BLOCK DIAGRAM OF PROJECTED STRUCTURE}

The implementation of this work is given in this step. Figure 5 shows suggest Method For Iris Recognition. Here during this unit diagram of prompt structure is given.

\section{A. Images Which are Test}

The database utilized for this object is CASIA.V4. The total database of this segment was searched for Iris pictures. Here there are 20 people groups dataset is to be considered for the examination.

\section{B. Pre-processing and De-noising}

Iris Recognition a ways off (IAAD) is utilized to improve the differentiation of the picture. Middle based channels are utilized to evacuate the sound introduces in the debased iris pictures. In pre-handling, the sign to-commotion portion of iris picture profile is upgraded additionally for this goal.

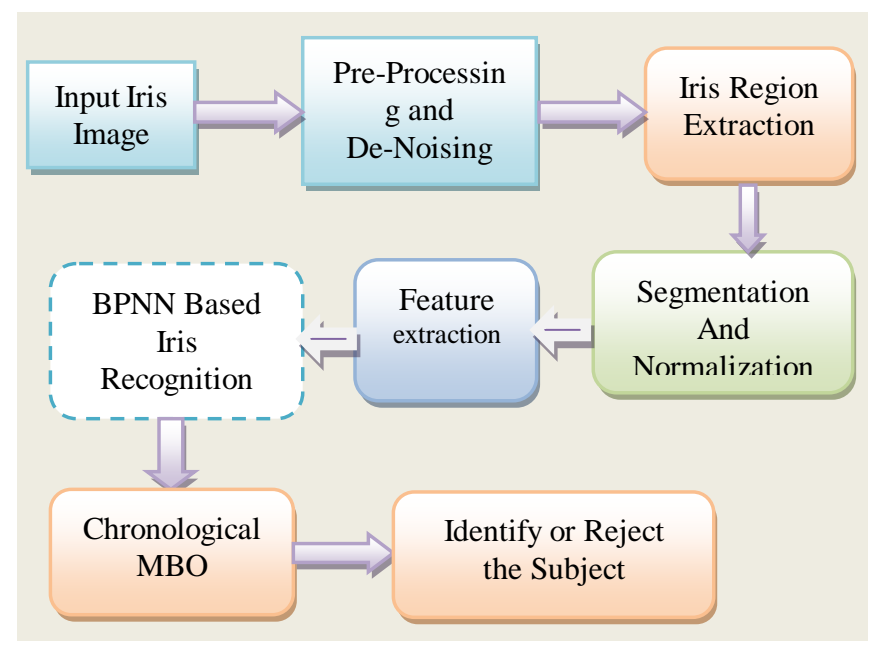

Fig. 5. Suggest Method For Iris Recognition.

\section{Hough Transform}

The Hough transform is used to extracts the different curves or shapes of an iris image.

\section{Segmentation and Normalization}

The division of the districts can occur by considering comparable properties of an iris picture. A portion of the comparable properties are shading, brilliance, differentiate, surface, dark level, and so forth. In this division step, the iris picture is part into disparate outskirts. The portioned iris picture is set up by utilizing a standardization calculation. The fragmented iris picture is utilized for the future extraction process. Because of the shifting position of an individual and the camera, the iris picture is exceptionally influenced by mutilation.

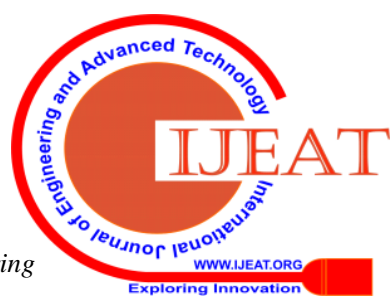


Along these lines standardization is utilized to make up for this issue. The Daugman's Rubber Sheet Model is use for this reason.

\section{E. Feature Extraction}

The major plan of the BPNN presents 1 info layer and least 1 shrouded layer pursued by yield layer. For preparing multi-layer artificial neural system Back Propagation Neural Network (BPNN) is normally utilized. PCA is an ideal plan to pack the high dimensional vectors into the low dimensional vectors and register the parameters from the information legitimately. The ScatT-Loop generator is use to remove the various highlights of an iris image. The ScatT-Loop creates the surface highlights for precise iris acknowledgment to remarkably recognize the people. Administrator in LGP uses the angle pixel esteems and is resolved as the force esteem. Distinctive changes shows in this progression are utilized to compute the surface highlights for the iris picture.

\section{F. Deep Belief Network (DBN)}

The powerful acknowledgment is acquired by the ideal tuning of the DBN classifier utilizing the Chronological MBO calculation. By utilizing Chronological MBO calculation we can gauge or characterize exact Iris picture. The dimensionally decreased highlights got utilizing PCA is bolstered as contribution to DBN to perceive the people.

Table 1 shows the literature survey of different iris recognition system. The comparison of different research work is shown in this table.

\section{DISCUSSION}

There are lots of difficulties occurs while capturing iris image. This can ne occur due to the small size of iris as compared to the distance in which the picture captured. Also very less volume of iris is captured due to the small size of iris, camera diffraction, acquisition distance, human machine interference, etc. This types of difficulties goes on increasing if the distance increases. To avoid this types of problems much many techniques are designed. The techniques which are used to solve these problems are use moderate hardware system, reduces the noise effects and other distortions, focus to increase the quality of input picture, use of larger megapixel cameras, Wave front Coding, use of telescope, etc.

Table- I: Litrature Summery fo Iris Recognition System.

\begin{tabular}{|c|c|c|c|c|c|c|}
\hline Approaches & Pre-process & Segmentation & Texture & Classifier & Database & Recognition \\
\hline $\begin{array}{l}\text { Nie et al. } \\
{[49]}\end{array}$ & $\begin{array}{l}\text { Retinex image } \\
\text { development } \\
\text { picture } \\
\text { whitening }\end{array}$ & $\begin{array}{l}\text { Set eyes Use average of } \\
\text { eyes' corners to normalize } \\
\text { for revolving and scale }\end{array}$ & $\begin{array}{l}\text { DSIFT CRBM } \\
\text { unverified } \\
\text { learning facial } \\
\text { appearance }\end{array}$ & $\begin{array}{l}\text { Supervised Mahalanobis } \\
\text { Score-level combination } \\
\text { of CRBM and DSIFT }\end{array}$ & $\begin{array}{l}\text { UBIPr: : Visible/4-8m } \\
344 \text { subjects }\end{array}$ & $\begin{array}{l}\text { Best: }{ }^{\text {CRBM }}+ \\
\text { DSIFT: } 6.4 \% \text { EER }\end{array}$ \\
\hline $\begin{array}{l}\text { Uzair et al. } \\
{[50]}\end{array}$ & $\begin{array}{l}\text { Eliminate } \\
\text { mysterious and } \\
\text { no eye frames in } \\
\text { the video } \\
\text { sequences }\end{array}$ & $\begin{array}{l}\text { Physically locate eyes' } \\
\text { corners revolution and } \\
\text { balance normalization }\end{array}$ & $\begin{array}{l}\text { Raw pixel } \\
\text { standards LBP } \\
\text { PCA coefficients } \\
\text { LBP + PCA }\end{array}$ & $\begin{array}{l}\text { Categorize based on } \\
\text { several images to deal } \\
\text { with variations MDA, } \\
\text { MMD, DCC, SANP, } \\
\text { CHISD,AHISD. }\end{array}$ & $\begin{array}{l}\text { MBGC: : NIR/3m } 85 \\
\text { subjects }\end{array}$ & $\begin{array}{l}\text { Best: SANP: } 97.7 \% \\
\text { IR and } 87.65 \% \text { VR } \\
\text { at } 0.001 \text { FAR }\end{array}$ \\
\hline $\begin{array}{l}\text { Smereka et } \\
\text { al. [51] }\end{array}$ & $\begin{array}{l}\text { Enlightenment } \\
\text { normalization }\end{array}$ & $\begin{array}{l}\text { Physically select } 4 \text { unusual } \\
\text { sizes of a periocular egion }\end{array}$ & PDM m-SIFT & $\begin{array}{l}\text { Correlation distance } \\
\text { Euclidean distance }\end{array}$ & $\begin{array}{l}\text { MBGC: : NIR/3m } 136 \\
\text { subjects UBIPr : } \\
\text { Visible/4-8m } 259 \\
\text { subjects }\end{array}$ & $\begin{array}{l}\text { Best: PDM MBGC: } \\
\text { 0.18EER UBIPr: } \\
\text { 0.06EER Visible: } \\
\text { larger periocular size } \\
\text { better NIR: smaller } \\
\text { better }\end{array}$ \\
\hline $\begin{array}{l}\text { Juefei-Xu et } \\
\text { al. [52] }\end{array}$ & $\begin{array}{l}\text { Enlightenment } \\
\text { normalization by } \\
\text { MSR }\end{array}$ & $\begin{array}{l}\text { Utilize eyes' focuses to } \\
\text { standardize for scale, turn, } \\
\text { and yield to a fixed size of } \\
50 \times 128\end{array}$ & $\begin{array}{l}\text {-Subspace } \\
\text { modeling } \\
\text { (KCFA, KDA, } \\
\text { UDP, PCA) } \\
\text { LBP -DT-LBP }\end{array}$ & $\begin{array}{ll}\text { Normalized } & \text { Cosine } \\
\text { Distance (NCD) } & \end{array}$ & $\begin{array}{l}\text { FRGC v2.0 : Visible/ } \\
222 \text { train, } 466 \text { target } \\
\text { subjects }\end{array}$ & $\begin{array}{l}\text { DT-LBP: } 75.1 \% \mathrm{VR} \\
\text { at } 0.1 \% \text { FAR, } 15.3 \% \\
\text { improvement over } \\
\text { LBP features }\end{array}$ \\
\hline $\begin{array}{l}\text { Proenca et } \\
\text { al. [53] }\end{array}$ & $\begin{array}{l}\text { Propose } 7 \\
\text { classes(glass, } \\
\text { skin, hair, } \\
\text { iris,sclera, } \\
\text { eyebrows,eyelas } \\
\text { hes, and) a pixel } \\
\text { in the periocular } \\
\text { has a place to }\end{array}$ & $\begin{array}{l}\text { Three-layer neural systems } \\
\text { used to gauge the class and } \\
\text { nearby insights of every } \\
\text { pixel - Calculate unary and } \\
\text { pairwise possibilities for a } \\
\text { MRF - Mask hair and glass } \\
\text { pixels. }\end{array}$ & $\begin{array}{ll}\text {-Global: } & \text { SIFT } \\
\text {-Local: } & \text { LBP, } \\
\text { HOG } & \end{array}$ & $\begin{array}{l}\text {-Euclidean distance } \\
\text {-Score-level fusion }\end{array}$ & $\begin{array}{l}\text { UBIRIS v2.0 : } \\
\text { Visible/4-8m } 5551 \\
\text { images }\end{array}$ & $\begin{array}{l}\text { Baseline: } 0.128 \mathrm{EER} \\
\text { vs. Improved ROIs: } \\
\text { 0.095EER }\end{array}$ \\
\hline $\begin{array}{l}\text { Mahalingam } \\
\text { et al. [54] }\end{array}$ & $\begin{array}{lr}\text { Apply } & \text { Wiener } \\
\text { channel } & \text { to } \\
\text { evacuate } & \\
\text { subsidiary } & \\
\text { clamor } & \end{array}$ & $\begin{array}{l}\text { Utilize eyes' focuses to } \\
\text { standardize for revolution } \\
\text { and scale yield to a fixed } \\
\text { size }\end{array}$ & $\begin{array}{l}\text { Three-Patch } \\
\text { LBP LBP HOG } \\
\text { SIFT }\end{array}$ & Euclidean distance & $\begin{array}{lr}\text { Transgender } & : \\
\text { Visible/11 } & \text { subjects } \\
\text { encountering } & \text { sexual } \\
\text { orientation change }\end{array}$ & $\begin{array}{ll}\text { TPLBP: } & 0.29 \mathrm{EER} \\
\text { LBP: } & 0.37 \mathrm{EER} \\
\text { HOG: } & 0.35 \mathrm{EER} \\
\text { SIFT: } 0.40 \mathrm{EER}\end{array}$ \\
\hline
\end{tabular}




\begin{tabular}{|c|c|c|c|c|c|c|}
\hline $\begin{array}{l}\text { Sharma et } \\
\text { al. [55] }\end{array}$ & $\begin{array}{l}\text { Eye organize } \\
\text { standardized }\end{array}$ & Physically find eyes & $\begin{array}{l}\text { PHOG (Pyramid } \\
\text { HOG) - } 2 \\
\text { shrouded layers } \\
\text { neural system to } \\
\text { learn highlights } \\
\text { on2 diverse } \\
\text { ghastly pictures }\end{array}$ & & $\begin{array}{l}\text { IIITDMultispectralPe } \\
\text { riocular : } 3 \text { spectrum: } \\
\text { Visible/ } 1.3 \mathrm{~m} \text {, } \\
\text { NIR/0.15m, } \\
\text { NightVision } / 1.3 \mathrm{~m} 62 \\
\text { subjects }\end{array}$ & $\begin{array}{l}30-50 \% \\
\text { acknowledgment } \\
\text { improvement }\end{array}$ \\
\hline $\begin{array}{l}\text { Juefei-Xu et } \\
\text { al. [56] }\end{array}$ & $\begin{array}{l}\text { Enlightenment } \\
\text { standardized }\end{array}$ & $\begin{array}{l}\text { Key focuses ASM Rotation } \\
\text { and eye arrange } \\
\text { standardized, Pose redress } \\
\text { Pose amendment }\end{array}$ & $\begin{array}{l}\text { Walsh-Hadamar } \\
\mathrm{d} \text { change } \\
\text { LBP-Kernel } \\
\text { class reliance } \\
\text { include } \\
\text { examination } \\
\text { (KCFA) }\end{array}$ & $\begin{array}{ll}\text { Normalized } & \text { cosine } \\
\text { distance(NCD) } & \end{array}$ & $\begin{array}{lr}\text { Compass } & : \\
\text { Visible/10-20m40 } \\
\text { subject } \quad \text { swith } \\
\text { impediment } & \text { and } \\
\text { articulation } & \end{array}$ & $\begin{array}{l}60.7 \% \text { VRat } \\
\text { FAR(16.9\% } \\
\text { improvement } \\
\text { full face) }\end{array}$ \\
\hline $\begin{array}{l}\text { Proenca et } \\
\text { al. [57] }\end{array}$ & $\begin{array}{l}\text { Articulation } \\
\text { remuneration by } \\
\text { Global Coherent } \\
\text { Elastic Graph } \\
\text { Matching } \\
(\text { GC-EGM) }\end{array}$ & & $\begin{array}{lr}\text {-Global: } & \text { SIFT } \\
\text {-Local: } & \text { HOG, } \\
\text { LBP } & \end{array}$ & $\begin{array}{l}\text {-Euclidean distance } \\
\text {-Score-level fusion }\end{array}$ & $\begin{array}{l}\text { Face Express UBI : } \\
\text { Visible/5-6m } \\
\text { variations } \\
\text { appearance }\end{array}$ & 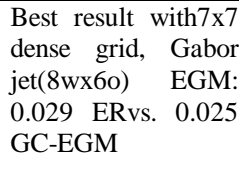 \\
\hline $\begin{array}{l}\text { Padole et al. } \\
{[58]}\end{array}$ & $\begin{array}{l}\text { llumination } \\
\text { Compensation } \\
\text { (IC) } \\
\text { homomorphic, } \\
\text { Pose } \\
\text { Compensation } \\
\text { (PC) by } \\
\text { Projective } \\
\text { Transformation }\end{array}$ & & 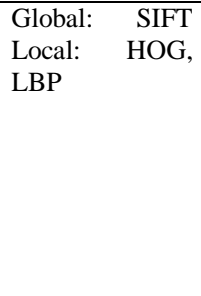 & $\begin{array}{l}\text {-Euclidean distance } \\
\text {-Score-level fusion }\end{array}$ & $\begin{array}{l}\text { UBIPosePr : } \\
\text { Visible/5-6m varieties } \\
\text { in enlightenment and } \\
\text { posture and posture. }\end{array}$ & $\begin{array}{l}\text { IC: } 35.0 \% \text { EER vs. } \\
42.6 \% \text { no IC PC: } \\
36.6 \% \text { EER } \\
41.3 \% \text { no PC }\end{array}$ \\
\hline $\begin{array}{l}\text { Padole et al. } \\
{[59]}\end{array}$ & $\begin{array}{l}\text { Use eye corners } \\
\text { to recognize and } \\
\text { standardize } \\
\text { periocular }\end{array}$ & $\begin{array}{l}\text {-Global: SIFT } \text {-Local: } \\
\text { HOG, LBP }\end{array}$ & $\begin{array}{l}\text { Euclidean } \\
\text { separation } \\
\text { Score-level } \\
\text { combination } \\
\end{array}$ & $\begin{array}{l}\text { UBIPr : Visible } / 4-8 \mathrm{~m} \\
\text { varieties in posture, } \\
\text { impediment scale and } \\
\text { pigmentation }\end{array}$ & & \\
\hline $\begin{array}{l}\text { Adam et al. } \\
{[60]}\end{array}$ & $\begin{array}{l}\text { - Remove dim, } \\
\text { obscure edges - } \\
\text { Hist leveling - } \\
\text { Mask eyes by } \\
\text { oval }\end{array}$ & $\begin{array}{l}\text { Find eye focuses } \begin{array}{r}\text { No } \\
\text { standardization }\end{array} \text { Fixed } \\
\text { harvest } 601 \times 601\end{array}$ & $\begin{array}{l}\text { Hereditary based } \\
\text { Type II highlight } \\
\text { extraction } \\
\text { framework to } \\
\text { upgrade } \\
\text { capabilities } \\
\text { returned by LBP }\end{array}$ & $\begin{array}{l}\text { Bhattacharya coefficients } \\
\text { for shading histogram, } \\
\text { City obstruct for LBP } \\
\text { surface }\end{array}$ & $\begin{array}{l}\text {-MBGC: } \quad \text { NIR/3m } \\
\text {-FRGC: Visible, }\end{array}$ & $\begin{array}{l}10 \% \text { recognition } \\
\text { accuracy } \\
\text { improvement }\end{array}$ \\
\hline $\begin{array}{l}\text { Miller et al. } \\
{[61]}\end{array}$ & $\begin{array}{l}\text { - Remove dim, } \\
\text { obscure edges - } \\
\text { Hist leveling - } \\
\text { Mask eyes by } \\
\text { oval }\end{array}$ & $\begin{array}{l}\text { Find eye focuses } \begin{array}{l}\text { No } \\
\text { standardization }\end{array} \\
\text { harvest } 601 \times 601\end{array}$ & $\begin{array}{l}\text { LBP Color } \\
\text { histograms No } \\
\text { global }\end{array}$ & $\begin{array}{l}\text { Bhattacharya coefficients } \\
\text { for shading histogram, } \\
\text { City obstruct for LBP } \\
\text { surface }\end{array}$ & $\begin{array}{l}\text {-MBGC: } \quad \mathrm{NIR} / 3 \mathrm{~m} \\
\text {-FRGC: Visible, }\end{array}$ & $\begin{array}{ll}\text { Left NIR: } 81 \% & \text { Right } \\
\text { NIR: } \quad 87 \% & \text { Left } \\
\text { Visible: } 90 \% & \text { Right } \\
\text { Visible: } 88 \% & \end{array}$ \\
\hline $\begin{array}{l}\text { Woodard et } \\
\text { al. [62] }\end{array}$ & $\begin{array}{l}\text { - Remove dim, } \\
\text { obscure edges - } \\
\text { Hist leveling - } \\
\text { Mask eyes by } \\
\text { oval }\end{array}$ & $\begin{array}{l}\text { Find eye focuses } \begin{array}{l}\text { No } \\
\text { standardization }\end{array} \text { Fixed } \\
\text { harvest } 601 \times 601\end{array}$ & $\begin{array}{l}\text { LBP Color } \\
\text { histograms No } \\
\text { global }\end{array}$ & $\begin{array}{l}\text { Bhattacharya coefficients } \\
\text { for shading histogram, } \\
\text { City obstruct for LBP } \\
\text { surface }\end{array}$ & $\begin{array}{l}\text {-MBGC: } \quad \text { NIR/3m } \\
\text {-FRGC: Visible, }\end{array}$ & 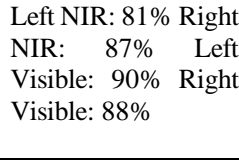 \\
\hline Xu et al. [63] & Light difference & $\begin{array}{l}\text { - Use iris focuses to } \\
\text { standardize, interpretation, } \\
\text { scale and revolution }\end{array}$ & $\begin{array}{l}\text { Local:DWT,Ga } \\
\text { bor,LoG } \\
\text {-Global:SIFT,S } \\
\text { URF }\end{array}$ & $\begin{array}{ll}\text { Manhattan } & \text { distance } \\
\text { Euclidean } & \text { distance } \\
\text { Cosine distance } & \end{array}$ & & $\begin{array}{l}\text { Best DWT + LBP } \\
53.2 \%\end{array}$ \\
\hline $\begin{array}{l}\text { Bharadwaj } \\
\text { et al. [64] }\end{array}$ & $\begin{array}{l}\text { Local contrast } \\
\text { normalized }\end{array}$ & $\begin{array}{l}\text {-Local: CLBP } \\
\text {-Global: GIST encoding } \\
\text { ruggedness, expansion, } \\
\text { roughness, naturalness and } \\
\text { openness. }\end{array}$ & $\begin{array}{l}\text { - X } 2 \text { distance } \\
\text {-Fused scores: } \\
\text { weighed sum }\end{array}$ & & & \\
\hline $\begin{array}{l}\text { Park et al. } \\
{[65]}\end{array}$ & $\begin{array}{l}\text { - Use iris focuses } \\
\text { to standardize } \\
\text { interpretation } \\
\text { and scale. }\end{array}$ & & $\begin{array}{l}\text {-Global: SIFT } \\
\text { Local HOG, } \\
\text { LBP }\end{array}$ & $\begin{array}{l}\text { Euclidean distance, Score } \\
\text { level fusion }\end{array}$ & $\begin{array}{l}30 \text { subjects visible/1.2 } \\
\text { m } 958 \text { images }\end{array}$ & $\begin{array}{l}\text {-Without eyebrow } \\
76.7 \% \\
\text { With eyebrow- } 80 \%\end{array}$ \\
\hline
\end{tabular}

DCC: Discriminative Canonical Correlation

DT-LBP: Discrete Transform encoded Local Binary Pattern PDM: Probabilistic Deformation Models UDP: Unsupervised Discriminant Projection SANP: Sparse Approximated Nearest Point
m-SIFT: Modified SIFT

ER: Error Rate

GEMs: Generic Elastic Models

MSR : Multi-Scale Retinex

VR: Verification Rate
MDA: Manifold Discriminant Analysis CHISD: Convex Hull Image Set Distance MMD: Manifold-Manifold Distance EGM : Elastic Graph Matching AHISD: Affine Hull Image Set Distance
- For the Hardware / Software design point of view for IAAD some modifications are required. Few of them are listed here:-

- The hardware should provide a complete optical solution for IAAD.

- Poor or ill-advised brightening can debase the recognition execution by producing low-quality, unusable pictures. Therefore, the sufficient light is 
properly illuminated to capture the specific eye region.

- Use the camera with high resolution so that it can capture the accurate picture with low noise.

- Use modified algorithms for image segmentation, normalization, future extraction and matching, etc.

Table- II: IAAD Implementation

\begin{tabular}{|c|l|l|l|l|l|}
\hline Structure & $\begin{array}{l}\text { Distan } \\
\text { ce } \\
\text { detecte } \\
\text { d }\end{array}$ & $\begin{array}{l}\text { Mot } \\
\text { ion }\end{array}$ & Wavelength & $\begin{array}{l}\text { Size of } \\
\text { Picture }\end{array}$ & $\begin{array}{l}\text { Precisi } \\
\text { on }\end{array}$ \\
\hline Wheeler [39] & 1.5 & No & NIR 810nm & ---- & ---- \\
\hline De Villar [40] & 30 & No & NIR & ---- & ---- \\
\hline CyLab [41] & $8-12$ & Yes & NIR 850nm & ---- & ---- \\
\hline Fancourt[42] & $5-10$ & No & NIR 880nm & 50 & $\begin{array}{l}95-100 \\
\%\end{array}$ \\
\hline Proenca [43] & $4-8$ & Yes & Visible & $261 / 15$ & ---- \\
\hline EagleEye [44] & $3-6$ & No & NIR laser & 13 & $92 \%$ \\
\hline CASIA [45] & 3 & No & NIR & $\begin{array}{l}142 / 30- \\
50\end{array}$ & $94 \%$ \\
\hline IOM[46] & 3 & Yes & NIR 850nm & $119 / 15$ & $99 \%$ \\
\hline Yoon [47] & $1.5-10$ & No & NIR 830nm & ---- & ---- \\
\hline MERL [48] & $1.2-1.8$ & No & Visible & $10 / 4$ & ---- \\
\hline
\end{tabular}

Table- III: Assessment of Different datasets helpful for IAAD study.

\begin{tabular}{|c|l|l|l|l|l|}
\hline Structure & $\begin{array}{l}\text { Distance } \\
\text { detected }\end{array}$ & $\begin{array}{l}\text { Number } \\
\text { of } \\
\text { subjects }\end{array}$ & $\begin{array}{l}\text { Both } \\
\text { eyes }\end{array}$ & $\begin{array}{l}\text { Number } \\
\text { of } \\
\text { picture }\end{array}$ & $\begin{array}{l}\text { Diame } \\
\text { ter of } \\
\text { iris(in } \\
\text { pixels) }\end{array}$ \\
\hline UBIRIS v2.0 & $4-8$ & 261 & Yes & 11102 & 110 \\
\hline MBGC & 3 & 129 & Yes & $\begin{array}{l}628 \text { NIR } \\
\text { videos }\end{array}$ & 120 \\
\hline CASIA-iris-distance & 3 & 142 & Yes & 2567 & 180 \\
\hline
\end{tabular}

Table 2 shows review of different iris-recognition-at-a-distance $\quad$ (IAAD) system implementation.

Assessment of different datasets helpful for IAAD study is shown in table 3 .

\section{CONCLUSION}

Iris recognition at a space is used in large amount of real time applications. A powerful iris acknowledgment framework for individual distinguishing proof is available in this article. With the assistance of the double iris division false reaction is decreases. The pointless foundation pictures are additionally expelled with the assistance of picture division process. Last several years most of the improvements are occurred in a IAAD systems. Some of the improvements are improved segmentation and feature extraction, quality enhancement and classification. As compared to steady objects, the acquisition of picture of moving object. extending the distance from a few meters to tens of meters. Also, many problems of iris recognition were solved like as human-machine interface, image acquisition, and image processing problems.

\section{REFERENCES}

[1] Defense Advanced Research Project, Human ID at a Distance http://infowar.net/tia/www.darpa.mil/iao/HID.htm , 2012

[2] Long range iris recognition: A survey Kien Nguyen a , * , Clinton Fookes a, Raghavender Jillela b, Sridha Sridharan a, Arun Ross c

[3] .NIST , IREX III - Performance of Iris Identification Algorithms, Technical Report NIST Interagency Report 7836, 2012.

[4] NIST , IREX IV - Evaluation of Iris Identification Algorithms, Technical Report NIST Interagency Report 7949, 2013

[5] T. Tan , Iris Recognition:Fundamentals and State-of-the-Art, Technical Report, National Laboratory of Pattern Recognition (NLPR), Chinese Academy of Sci- encesâüInstitute of Automation (CASIA), 2013.

[6] K.W. Bowyer, K. Hollingsworth, P.J. Flynn , Image understanding for iris bio- metrics: a survey, Comput. Vis. Image Underst. 110 (2008) 281-307

[7] K.W. Bowyer, K. Hollingsworth, P.J. Flynn, Handbook of Iris Recognition, Springer-Verlag, UK.

[8] Kumar A and Tan C.W. IEEE Transactions on Information Forensics and Security, vol. 9, no. 9, pp.1518-1526, 2014 . "Efficient and accurate at-a-distance iris recognition using geometric key-based iris encoding",.

[9] Kumar A and Tan C.W. "Efficient and accurate at-a-distance iris recognition using geometric key-based iris encoding”, IEEE Transactions on Information Forensics and Security, vol. 9, no. 9, pp.1518-1526, 2014.

[10] Chellappa R, Puertas M. and Pillai J.K., "Cross-sensor iris recognition through kernel learning", IEEE transactions on pattern analysis and machine intelligence, vol. 36, no. 1, pp.73-85, 2014.

[11] Kim T, Byeon O. Lee K., and Lim S., "Efficient iris recognition through improvement of feature vector and classifier", ETRI journal, vol. 23, no. 2, pp.61-70, 2001.

[12] Kumar A and Tan C.W. "Accurate iris recognition at a distance using stabilized iris encoding and Zernike moments phase features", IEEE Transactions on Image Processing, vol. 23, no. 9, pp.3962-3974, 2014.

13] IEEE transactions on pattern analysis and machine intelligence, vol. 15, no. 11, 1993, pp. 1148-1161. J. G. Daugman, "High confidence visual recognition of persons by a test of statistical independence",

14] G. P. M. Paiva et al., M. V. Priya and K. A. Raghavi, "Human iris recognition using fuzzy neural concepts", The International Conference on Bioscience, Biochemistry and Bioinformatics (IPCBEE), 2011, pp. 256-260.

5] D. T. Santhanam and M. Gopikrishnan "A tradeoff between template size reduction and computational accuracy in Iris Patterns Recognition using Neural Networks", seec proceedings by, SEEC, vol., no., 2010.

[16] F. Setoudeh, H. Shahhosseini, and L. F. Araghi, "IRIS recognition using neural network", Proceedings of the international multiconference of engineers and computer scientists, 2010.

[17] K. Altunkaya and R. H. Abiyev "Personal iris recognition using neural network", International Journal of Security and its Applications, vol. 2, no. 2, 2008, pp. 41- 50 .

[18] B. Ergen, and O. F. Soylemez "Circular hough transform based eye state detection in human face images", Signal Processing and Communications Applications Conference (SIU), 2013 21st, 2013, pp. 1- 4.

[19] C. Grosan, A. Abraham and A. E. Hassanien, and "Spiking neural network and wavelets for hiding iris data in digital images", Soft Computing, vol. 13, no. 4, 2009, pp. 401-416.

[20] T. Tan, Y. Wang, and L. Ma, "Iris recognition using circular symmetric filters", Pattern Recognition, 2002. Proceedings. 16th International Conference on, 2002, pp. 414-417.

[21] G. L. Green et al., J. C. Asmuth and R. P. Wildes, "A system for automated iris recognition", Applications of Computer Vision, 1994. Proceedings of the Second IEEE Workshop on, 1994, pp. 121-128.

[22] B. Boashash and W. W. Boles "A human identification technique using images of the iris and wavelet transform", IEEE transactions on signal processing, vol. 46, no. 4, 1998, pp. 1185-1188.

[23] L. Masek, "Recognition of human iris patterns for biometric identification", The University of Western Australia, vol. 2, no., 2003.

[24] Alaa S. Al Waisy, Rami Qahwaji, Stanley Ipson, Shumoos Al Fahdawi and Tarek A. M. Nagem," A multibiometric iris recognition system based on a deep learning approach", Pattern Analysis and Applications, Vol :21,no: 3, pp :783-802, August 2018.

[25] Liu N., Liu J., Sun Z. and Tan T., "A Code-Level Approach to Heterogeneous Iris Recognition", IEEE Transactions on Information Forensics and Security, vol. 12, no. 10, pp.2373-2386, 2017. 
[26] Ahmadi N. and Akbarizadeh G., "Hybrid robust iris recognition approach using iris image pre-processing, two-dimensional gabor features and multi-layer perceptron neural network/PSO”, IET Biometrics, vol. 7, no. 2, pp.153-162, 2017.

[27] Nguyen K., Fookes C., Ross A. and Sridharan S., "Iris recognition with off-the-shelf CNN features: A deep learning perspective", IEEE Access, vol. 6, pp.18848-18855, 2018.

[28] Tan C.W. and Kumar A., "Accurate iris recognition at a distance using stabilized iris encoding and Zernike moments phase features", IEEE Transactions on Image Processing, vol. 23, no. 9, pp.3962-3974, 2014.

[29] Othman N. and Dorizzi B., "Impact of quality-based fusion techniques for video-based iris recognition at a distance," IEEE transactions on Information Forensics and Security, vol. 10, no. 8, pp.1590-1602, 2015.

[30] Tan C.W. and Kumar A., "Efficient and accurate at-a-distance iris recognition using geometric key-based iris encoding", IEEE Transactions on Information Forensics and Security, vol. 9, no. 9, pp.1518-1526, 2014.

[31] N. Pattabhi Ramaiah and Ajay Kumar, "Toward more accurate iris recognition using cross-spectral matching", IEEE transactions on Image processing, vol. 26, no. 1, pp.208-221, 2017.

[32] 32 C. Agurto, V. Murray, E. Barriga, S. Murillo, M. Pattichis, H.Davis, et al., Multi scale AM-FM methods for diabetic retinopathy lesion detection, IEEE Transactions on Medical Imaging 29 (2010) 502-512.

[33] 33 G. Fahmy, "Super-resolution construction of iris image low resolution face video," in Signal Processing and Its Applications, 2007. ISSPA 2007. 9th International Symposium.

[34] C. Agurto, Y. Honggang, V. Murray, M.S. Pattichis, S. Barriga,W. Bauman, et al., Detection of neo vascularization in the optic disc using an AM-FM representation, granulometry, and vessel segmentation, in: Annual International Conference of the IEEE, Engineering in Medicine and Biology Society (EMBC), 2012, pp. 4946-4949.

[35] K.A. Goatman, A.D. Fleming, S. Philip, G.J. Williams, J.A.Olson, P.F. Sharp, Detection of new vessels on the optic discusing retinal photographs, IEEE Transactions on Medical Imaging 30 (2011) 972.

[36] C.N. Doukas, I. Maglogiannis, A.A. Chatziioannou, Computer-supported angiogenesis quantification using image analysis and statistical averaging, IEEE Transactions on Information Technology in Biomedicine 12 (2008)650-657.

[37] Nadia Othman and Bernadette Dorizzi " Impact of Quality-Based Fusion Techniques for Video-Based Iris Recognition at a Distance", 1556-6013 (c) 2015 IEEE. Personal use is permitted, but republication/redistribution requires IEEE permission. See http://www.ieee.org/publications_standards/publications/rights/index.ht $\mathrm{ml}$ for more information.

[38] L. Zhang, Q. Li, J. You, D. Zhang, A modified matched filter with double-sided thresholding for screening proliferative diabetic retinopathy, IEEE Transactions on Information Technology in Biomedicine 13 (2009) 528-534.

[39] F. Wheeler, A. Perera, G. Abramovich, B. Yu, P. Tu, Stand-off iris recognition system, in: IEEE International Conference on Biometrics: Theory, Applications and Systems (BTAS), 1, 2008, pp. 1-7.

[40] J. De Villar, R. Ives, J. Matey, Design and implementation of a long range iris recognition system, in: Asilomar Conference on Signals, Systems and Com- puters (ASILOMAR), 2010, pp. 1770-1773.

[41] S. Venugopalan, U. Prasad, K. Harun, K. Neblett, D. Toomey, J. Heyman, M. Savvides, Long range iris acquisition system for stationary and mobile sub- jects, in: International Joint Conference on Biometrics (IJCB), 2011, pp. 1-8.

[42] C. Fancourt, L. Bogoni, K. Hanna, Y. Guo, R. Wildes, N. Takahashi, U. Jain, Iris recognition at a distance, in: Proceedings of the 2005 IAPR Conference on Audio and Video Based Biometric Person Authentication, USA, 2005, pp. 1-13.

[43] F. Bashir, D. Usher, P. Casaverde, M. Friedman, Video surveillance for biomet- rics: long-range multi-biometric system, in: IEEE International Conference on Advanced Video and Signal Based Surveillance, USA, 2008, pp. 175-182.

[44] W. Dong, Z. Sun, T. Tan, A design of iris recognition system at a distance, in: Chinese Conference on Pattern Recognition (CCPR), 2009, pp. 1-5.

[45] J. Matey, O. Naroditsky, K. Hanna, R. Kolczynski, D. LoIacono, S. Mangru,

[46] M. Tinker, T. Zappia, W. Zhao, Iris on the move: acquisition of images for iris recognition in less constrained environments, Proc. IEEE 94 (2006) 1936-1947.

[47] S. Yoon, K. Bae, K.R. Park, J. Kim, Pan-tilt-zoom based iris image capturing system for unconstrained user environments at a distance, in:
International Conference on Biometrics (ICB), Germany, 2007, pp. 653-662.

[48] 48 Mitsubishi Electric Research Lab, A system for automatic iris capturing, 2005, (http://www.merl.com/publications/TR2005-044/).

[49] L. Nie, A. Kumar, S. Zhan, Periocular recognition using unsupervised convolu- tional rbm feature learning, in: International Conference on Pattern Recogni- tion (ICPR), 2014, pp. 399-404.

[50] M. Uzair, A. Mahmood, A. Mian, C. McDonald, Periocular biometric recogni- tion using image sets, in: IEEE Workshop on Applications of Computer Vision (WACV), 2013, pp. 246-251.

[51] J. Smereka, B. Kumar, What is a good periocular region for recognition? in: IEEE International Conference on Computer Vision and Pattern Recognition Workshops (CVPRW), 2013, pp. 117-124.

[52] F. J. Xu, M. Savvides, Subspace-based discrete transform encoded local binary patterns representations for robust periocular matching on NIST's face recog- nition grand challenge, IEEE Trans. Image Process. 23 (2014) 3490-3505

[53] 201H. Proenca, J. Neves, G. Santos, Segmenting the periocular region using a hi- erarchical graphical model fed by texture/shape information and geometrical constraints, in: IEEE International Joint Conference on Biometrics (IJCB), 2014, pp. 1-7.

[54] 197G. Mahalingam, K. Ricanek, Is the eye region more reliable than the face? A preliminary study of face-based recognition on a transgender dataset, in: IEEE Sixth International Conference on Biometrics: Theory, Applications and Systems (BTAS), 2013, pp. 1-7.

[55] 199A. Sharma, S. Verma, M. Vatsa, R. Singh, On cross spectral periocular recog- nition, in: IEEE International Conference on Image Processing (ICIP), 2014, pp. 5007-5011.

[56] 200F. Juefei-Xu, M. Savvides, Unconstrained periocular biometric acquisition and recognition using COTS PTZ camera for uncooperative and non-cooperative subjects, in: IEEE Workshop on Applications of Computer Vision (WACV), 2012, pp. 201-208.

[57] 202 H.Proenca , J. Briceno , Periocular biometrics: constraining the elastic graph matching algorithm to biologically plausible distortions, IET Biom. 3 (2014) . 167-75

[58] 189C. Padole, H. Proenca, Compensating for pose and illumination in uncon- strained periocular biometrics, Int. J. Biom. 5 (2013). 336-59

[59] 198C. Padole, H. Proenca, Periocular recognition: analysis of performance degra- dation factors, in: International Conference on Biometrics (ICB), 2012, pp. 439-445.

[60] 194J. Adams, D. Woodard, G. Dozier, P. Miller, K. Bryant, G. Glenn, Genet- ic-based type ii feature extraction for periocular biometric recognition: less is more, in: International Conference on Pattern Recognition (ICPR), 2010, pp. 205-208.

[61] 192P. Miller, J. Lyle, S. Pundlik, D. Woodard, Performance evaluation of local ap- pearance based periocular recognition, in: IEEE International Conference on Biometrics: Theory Applications and Systems (BTAS), 2010a, pp. 1-6.

[62] 191D. Woodard, S. Pundlik, J. Lyle, P. Miller, Periocular region appearance cues for biometric identification, in: IEEE International Conference on Computer Vision and Pattern Recognition Workshops (CVPRW), 2010, pp. 162-169.

[63] 188J. Xu, M. Cha, J. Heyman, S. Venugopalan, R. Abiantun, M Savvides, Robust local binary pattern feature sets for periocular biometric identification, in: IEEE International Conference on Biometrics: Theory Applications and Sys- tems (BTAS), 2010, pp. 1-8.

[64] 196S. Bharadwaj, H. Bhatt, M. Vatsa, R. Singh, Periocular biometrics When iris recognition fails, in: IEEE International Conference on Biometrics: Theory Ap- plications and Systems (BTAS), 2010, pp. 1-6.

[65] 180U. Park, A. Ross, A. Jain, Periocular biometrics in the visible spectrum: a fea- sibility study, in: IEEE International Conference on Biometrics: Theory, Appli- cations, and Systems (BTAS), 2009, pp. 1-6. 


\section{AUTHORS PROFILE}

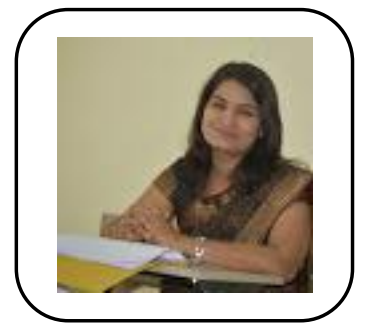

Ms.Swati D. Shirke holds an M.E.degree in Computer Science and Engineering from Pune University and is a research fellow in the Department of Computer Science and Engineering, Bharath Institute of Higher Education and Research, Bharath University. Her main area of interest includes pattern recognition, image processing, machine learning, She has published several papers in well known peer-reviewed journals.

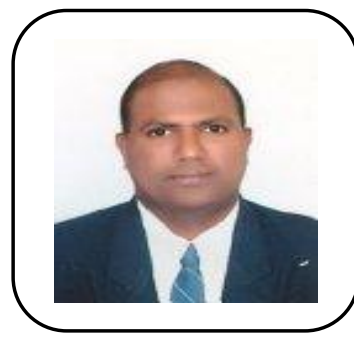

Dr. C. Rajabhushnam holds a Ph.D. in Neural Networks, from Louisiana State University, USA And he is a professor in the Department of In the Department of Computer Science and Engineering, Bharath Institute of Higher Education and Research, Bharath University. His main area of interest includes pattern recognition, image processing, and machine learning he has published several papers in well known peer-reviewed journals. 